\title{
Imaging features associated with survival outcomes among colorectal cancer patients with and without KRAS mutation
}

\author{
Julaluck Promsorn ${ }^{1 *}$ D, Payia Chadbunchachai ${ }^{1}$, Kulyada Somsap ${ }^{1}$, Krisada Paonariang $^{2}$, Prakasit Sa-ngaimwibool ${ }^{3}$, \\ Chaiwat Apivatanasiri ${ }^{3}$, Rita Maria Lahoud ${ }^{4}$ and Mukesh Harisinghani ${ }^{4}$
}

\begin{abstract}
Background: Mutations in Kirsten rat sarcoma proto-oncogene (KRAS) have been shown to be associated with advanced-stage colorectal cancer (CRC), negative disease outcomes, and poor response to treatment. The purpose of this study was to investigate which CT features are biomarkers for KRAS gene mutation and impact the survival outcomes of colorectal cancer patients.

Results: Of the 113 CRC patients included in the study, 46 had KRAS mutations (40.71\%) and 67 had no mutations (59.29\%). Regional lymph node necrosis was the only imaging feature significantly associated with KRAS mutation $(P=0.011)$. Higher T staging and liver, lung, and distant metastasis were prognostic factors for CRC $(P=0.014, P<$ $0.001, P=0.022, P<0.001$, respectively). There were no significant differences in overall survival between patients with KRAS mutations and those without $(P=0.159)$. However, in patients with no KRAS mutation, those with CRC on the left side had a significantly higher rate of survival than those with CRC on the right $(P=0.005)$.
\end{abstract}

Conclusion: Regional lymph node necrosis may be an imaging biomarker of CRC with KRAS mutation, possibly indicating poor prognosis.

Keywords: Colorectal cancer, KRAS mutation, CT, MRI

\section{Background}

There are approximately 1,000,000 annual cases of colorectal cancer $(\mathrm{CRC})$ causing more than 600,000 deaths worldwide [1]. Mutations in Kirsten rat sarcoma (KRAS) proto-oncogene have been shown to be associated with the disease, and tumors with these mutations are likely to be resistant to anti-epidermal growth factor receptor (EGFR) therapy [2-14]. Mutations in human KRAS are discovered in around $40 \%$ of metastatic colorectal cancer patients $[15,16]$. However, a combination of KRAS and b-Raf murine sarcoma viral oncogene homolog B1 (BRAF) mutation is found in only $0.001 \%$ of cases [17]. Many studies have found that some genetic mutations

\footnotetext{
* Correspondence: pjulaluck@kku.ac.th

${ }^{1}$ Department of Radiology, Faculty of Medicine, Khon Kaen University, Khon Kaen District 40002, Thailand

Full list of author information is available at the end of the article
}

are associated with more advanced stage of disease at onset, leading to limited treatment options, poor treatment response, and worse disease outcomes [4, 14]. Few randomized controlled trials such as CRYSTAL, PEAK, and PRIME have found adverse effects from a combination of anti-EGFR drugs and chemotherapy $[16,18,19]$. Studies have also found that KRAS mutations that involve codons 12 and 13 are associated with poorer overall survival rates [20-25].

National Comprehensive Cancer Network (NCCN) guidelines recommend testing for KRAS mutations in the initial diagnostic workup for metastatic colorectal cancer [5, 21, 26-28] as KRAS mutation is an important prognostic biomarker predicting survival outcomes in these patients [4, 14, 29]. Advancement of molecular biology and associated technologies has helped in the 
development of new chemotherapy regimens and novel targeted therapeutic agents for rectal cancer [3].

As far as imaging correlates between CRC and KRAS mutation, changes have been reported on magnetic resonance imaging (MRI) [30] between tumors with KRAS mutation than wild type. Published studies have found that the size of the primary rectal carcinomas differed significantly in patients with and without KRAS mutations [31]; certain MRI texture features were significantly associated with KRAS mutation status in patients with rectal cancer [32]. Rectal carcinoma with KRAS mutation were associated with higher $\mathrm{N}$ stage, polypoid mass with greater tumor length on MRI [33]. The parameter of apparent diffusion coefficient (ADC) of KRAS mutation colorectal cancer has also been shown to be lower compared to wild-type tumor groups [34]. Some studies have shown that colorectal cancer patients with KRAS mutations had a higher maximum standardized uptake value $\left(\mathrm{SUV}_{\max }\right)$ on FDG-PET than those without [35-39]. Although imaging modalities are crucial in preoperative evaluation and treatment planning, there is no consensus as to the associations between pretreatment imaging, especially computed tomography (CT) and these genetic mutations.

Further imaging findings that link KRAS mutations and patient survival may aid in determining treatment options and targeted therapeutics for advanced colorectal cancer. The aim of this study was to investigate CT features associated with survival outcomes among colorectal cancer patients with and without KRAS mutation.

\section{Methods}

\section{Patients}

This retrospective analytical study was approved by our institutional review board, and the requirement for patient consent was waived. At the tertiary care cancer center hospital at which this study was conducted, there were a total of 367 patients identified with pathologically proven CRC from January 1, 2009, to January 1, 2019. Of these, 113 patients were tested for KRAS gene mutations and also underwent rountine staging abdominal CT studies. Two hundred fifty-four were excluded due to having received previous treatment (surgery, chemotherapy, or radiotherapy), inadequate image quality, inadequate KRAS genetic mutation test results, and inadequate survival data.

\section{Imaging analysis and data collection}

All patients' epidemiological data and KRAS test results were obtained from the hospital's electronic medical records health object $(\mathrm{HO})$.

An experienced radiologist with more than 10 years of experience in abdominal imaging along with early career radiologist with 2 years of abdominal imaging experience evaluated the abdominal staging CT in consensus using a $2000 \times 2000$ picture archiving and communication system (PACS) workstation. Scans closest to the surgery were analyzed in random order with the researchers blinded to all clinical information. Features analyzed included tumor diameter, tumor length, tumor morphology, and tumor margin, pattern of tumor enhancement, local invasion of the peritoneum or an adjacent organ, regional or distant lymphadenopathy, and distal metastasis. All measurements were recorded in millimeters. Tumor location was recorded in relation to the cecum, ascending colon, hepatic flexure colon, transverse colon, splenic flexure colon, descending colon, sigmoid colon, and rectum. Tumors were considered left sided if located in distal $2 / 3$ of the transverse colon to anorectal region and right sided if located from cecum to proximal $2 / 3$ of the transverse colon [40].

The tumor sizes were measured in axial tumor length (ATL) on axial image and longitudinal tumor length (LTL) on coronal image; then, ATL/LTL were calculated. Tumor morphology was classified into polypoid, ulcerated, and circumferential wall thickening. The margin of the tumor was classified as either smooth, lobulated, or infiltrating. The enhancement pattern was classified as either homogeneous enhancement, heterogeneous enhancement in less than $50 \%$ of the tumor, and heterogeneous enhancement in $50 \%$ or more of the tumor.

Lymphadenopathy was defined as presence of any lymph node more than $5 \mathrm{~mm}$ or larger in short axis diameter and if there was presence of necrosis or heterogeneous enhancement within the enlarged lymph nodes or irregular border of the lymph node.

Finally, tumor $(\mathrm{T})$, nodes $(\mathrm{N})$, and metastases $(\mathrm{M})$ staging was determined following the 8th TNM staging system proposed by the American Joint Committee on Cancer.

\section{Imaging protocol \\ CT imaging protocol}

There were 90 patients in which abdominal CT imaging was performed using one of two spiral CT scan machines: a 128 spiral CT scanner (Brilliance iCT SP 128 slice, Philips Medical Systems, Netherland) with a slice thickness of $2 \mathrm{~mm}, 80 \mathrm{~mm}$ of detector cover, $0.27 \mathrm{~s}$ of rotation time, and $700 \mathrm{~mm}$ gantry aperture or a 256 slice spiral dual source dual energy CT scanner (Somatom Definition Flash 256 slice, Siemens Medical Solutions, Erlangen, Germany) with a slice thickness of $2 \mathrm{~mm}, 78$ $\mathrm{mm}$ of detector cover, $0.28 \mathrm{~s}$ of rotation time, and 780 $\mathrm{mm}$ gantry aperture. The abdominal CT protocol included a pre-contrast scan and portal venous phase (70- 
Table 1 Baseline characteristics of studied populations

\begin{tabular}{|c|c|c|c|}
\hline Baseline characteristics & Negative KRAS mutation & Positive KRAS mutation & $P$ value \\
\hline No. (\%) & 67 (59.29\%) & $46(40.71 \%)$ & \\
\hline Sex (\%) & & & 0.859 \\
\hline Male & $39(58.21)$ & $26(56.52)$ & \\
\hline Female & $28(41.79)$ & $20(43.48)$ & \\
\hline Age, years & & & 0.555 \\
\hline Mean (SD) & $58.21(11.28)$ & $59.39(9.05)$ & \\
\hline Median (min-max) & $59(29-86)$ & $59.5(42-82)$ & \\
\hline
\end{tabular}

$80 \mathrm{~s}$ after contrast injection). The contrast injection rate was about $5 \mathrm{ml} / \mathrm{s}(2 \mathrm{ml} / \mathrm{kg}$; not more than $120 \mathrm{ml})$. The remainder 23 patients underwent abdominal CT imaging at an outside institution. Pre-contrast and portal venousphase images were evaluated using a PACS.
Evaluation of overall survival

Overall survival was calculated based on the duration from pre-treatment abdominal CT until the date of death or the end of data collection (January 1, 2019). Median overall survival outcome is presented in months.

Table 2 The association between imaging characteristic and KRAS mutation based on an independent sample $t$ test or MannWhitney $U$ test

\begin{tabular}{|c|c|c|c|}
\hline Imaging variable & Negative KRAS mutation & Positive KRAS mutation & $P$ value \\
\hline Axial tumor length (ATL) $(\mathrm{cm})$ & $(n=69)$ & $(n=46)$ & \\
\hline Median (min-max) & $1.9(1.0-6.4)$ & $2.2(1.1-7.7)$ & 0.815 \\
\hline Mean (SD) & $2.37(1.12)$ & $2.35(1.08)$ & 0.937 \\
\hline Longitudinal tumor length $(\mathrm{LTL})(\mathrm{cm})$ & $(n=69)$ & $(n=46)$ & \\
\hline Median (min-max) & $6.3(1.3-15.0)$ & $6.0(1.28-16.0)$ & 0.564 \\
\hline Mean (SD) & $6.67(2.90)$ & $6.48(2.87)$ & 0.723 \\
\hline ATL/LTL & $(n=69)$ & $(n=46)$ & \\
\hline Median (min-max) & $0.35(0.12-1.75)$ & $0.38(0.08-2.19)$ & 0.521 \\
\hline Mean (SD) & $0.42(0.29)$ & $0.43(0.31)$ & 0.888 \\
\hline Tumor locations (\%) & $(n=69)$ & $(n=46)$ & 0.584 \\
\hline Left side & $61(88.41)$ & $39(84.78)$ & \\
\hline Right side & $8(11.59)$ & $7(15.22)$ & \\
\hline Tumor gross patterns (\%) & $(n=69)$ & $(n=46)$ & \\
\hline Polypoid & $30(43.48)$ & $23(50)$ & 0.568 \\
\hline Ulcerative & $3(4.35)$ & $1(2.17)$ & 0.649 \\
\hline Circumferential wall thickening & $42(60.87)$ & $23(50)$ & 0.258 \\
\hline Tumor margin (\%) & $(n=69)$ & $(n=46)$ & 0.390 \\
\hline Smooth & $0(0.00)$ & $1(2.17)$ & \\
\hline Lobulate & $69(92.54)$ & $43(93.48)$ & \\
\hline Infiltrating & $5(7.46)$ & $2(4.35)$ & \\
\hline Tumor enhancement patterns (\%) & $(n=69)$ & $(n=46)$ & 0.736 \\
\hline Homogenous & $7(10.14)$ & $4(8.70)$ & \\
\hline Heterogeneous $<50 \%$ & $25(31.88)$ & $12(26.09)$ & \\
\hline Heterogeneous $\geq 50 \%$ & $40(57.97)$ & $30(65.22)$ & \\
\hline T stage $(\%)$ & $(n=68)$ & $(n=46)$ & 0.955 \\
\hline 2 & $30(43.48)$ & $21(45.65)$ & \\
\hline 3 & $24(34.78)$ & $16(34.78)$ & \\
\hline 4 & $15(21.74)$ & $9(19.57)$ & \\
\hline
\end{tabular}


Table 3 The association between imaging characteristics and KRAS mutation according to a Pearson's Chi-square or Fisher's exact test

\begin{tabular}{|c|c|c|c|}
\hline Imaging variable & KRAS mutation (-) & KRAS mutation (+) & $P$ value \\
\hline Regional lymph node metastasis (\%) & $(n=67)$ & $(n=46)$ & 0.736 \\
\hline No & $6(8.96)$ & $5(10.87)$ & \\
\hline Yes & $61(91.04)$ & $41(89.13)$ & \\
\hline Necrosis & $(n=61)$ & $(n=41)$ & 0.011 \\
\hline No & $19(31.15)$ & $4(9.76)$ & \\
\hline Yes & $42(68.85)$ & $37(90.24)$ & \\
\hline Distant lymph node metastasis (\%) & & & 0.790 \\
\hline No & $51(76.12)$ & $34(73.91)$ & \\
\hline Yes & $16(23.88)$ & $12(26.09)$ & \\
\hline Liver metastasis (\%) & & & 0.167 \\
\hline No & $29(43.28)$ & $26(56.52)$ & \\
\hline Yes & $38(56.72)$ & $20(43.48)$ & \\
\hline Lung metastasis (\%) & & & 0.166 \\
\hline No & $61(91.04)$ & $37(82.22)$ & \\
\hline Yes & $6(8.96)$ & $8(17.78)$ & \\
\hline Bone metastasis (\%) & & & $>0.999$ \\
\hline No & $66(98.51)$ & $44(97.78)$ & \\
\hline Yes & $1(1.49)$ & $1(2.22)$ & \\
\hline
\end{tabular}

\section{Statistical analysis}

Continuous variables, including age and diameter of tumor, were compared between groups using an independent sample $t$ test or Mann-Whitney $U$ test as appropriate. Categorical variables, including KRAS mutation, sex, $\mathrm{T}$ stage, location of the tumor, lymph node metastasis, liver metastasis, lung metastasis, bone metastasis, peritoneal invasion, and distant metastasis, were compared between groups using Pearson's Chisquare or Fisher's exact test. Survival outcomes and recurrence rates were compared using a log-rank test. Survival was compared using a Kaplan-Meier graph. All statistical analyses were performed using STATA (version 10.1. Stata Corp LP, 4905, Lakeway Drive College Station, TX, USA).

\section{Results}

Baseline and population characteristics

Among the 113 (65 male and 48 female) CRC patients included in this study, $40.71 \%$ (46; $56.52 \%$ male; $43.48 \%$ female) had KRAS genetic mutations (age range 42 to 82 years; mean $59.39 \pm 9.05$ years), and $59.29 \%$ (67; $58.21 \%$ male; $41.79 \%$ female) in age from 29 to 86 years
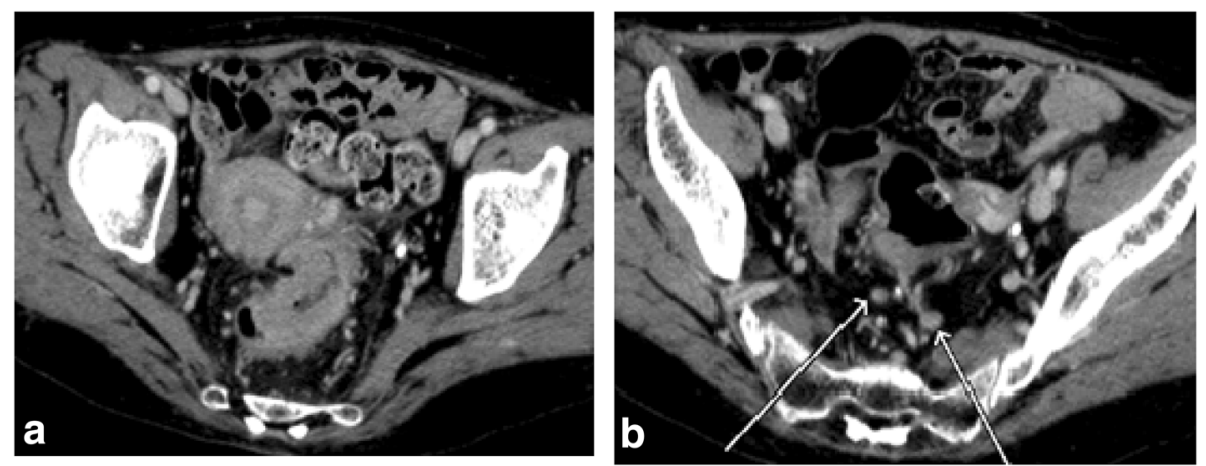

Fig. 1 A 57-year-old woman with rectosigmoid colon cancer and a wild-type KRAS mutation. The tumor exhibited a lobulated margin, circumferential wall thickening, and homogenous enhancement without adjacent organ invasion $(T$ stage $2 ; \mathbf{a})$ and two regional lymph nodes without necrosis ( $N$ stage 2; arrow; b) 

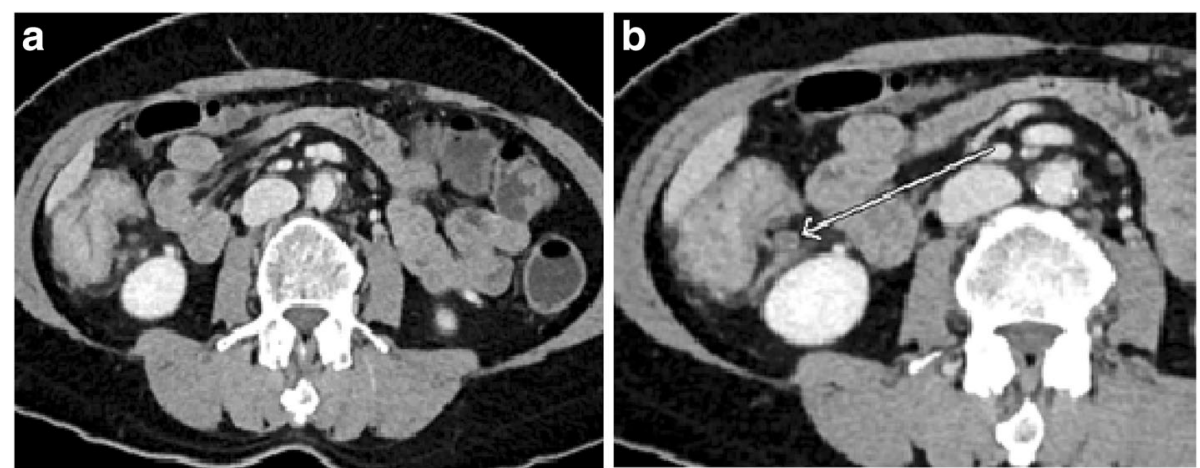

Fig. 2 A 54-year-old woman with ascending colon cancer and KRAS mutation. The tumor exhibited a polypoid appearance, lobulated margin, heterogenous enhancement less than 50 percent ( $($ stage $3 ; \mathbf{a}$ ), and necrosis of the regional lymph node metastasis (arrow; N stage 2; b)

old with a mean of $58.21 \pm 11.28$ did not have the mutation. The two groups did not differ significantly in terms of sex $(p=0.859)$. The mean age of patients with and without KRAS mutations did not differ significantly (58.21 years and 59.39 years, respectively; $P=0.555$; Table 1).

\section{Association between imaging features and KRAS mutation}

No significant difference was seen between the two groups in terms of ATL, LTL, ATL/LTL, tumor location, gross tumor patterns, tumor margins, tumor enhancement patterns, $\mathrm{T}$ staging, regional lymph node metastasis, distant lymph node metastasis, or distal organ metastasis (including liver, lung, and bone; Tables 2 and
$3)$. Only necrosis of the regional lymph node differed significantly $(P=0.111$; Table 3 , Figs. 1 and 2$)$.

The survival analysis outcome rates in the two groups There was no significant difference between KRAS groups in terms of surgical outcome $(P=0.159$; Fig. 3$)$. However, those in the KRAS mutation group had a lower survival rate.

\section{Comparison of tumor location and survival analysis between groups}

No significant difference was seen in survival rate among patients with left- and right-side in the KRAS mutation group $(P=0.379$; Fig. 4). However, in the KRAS-

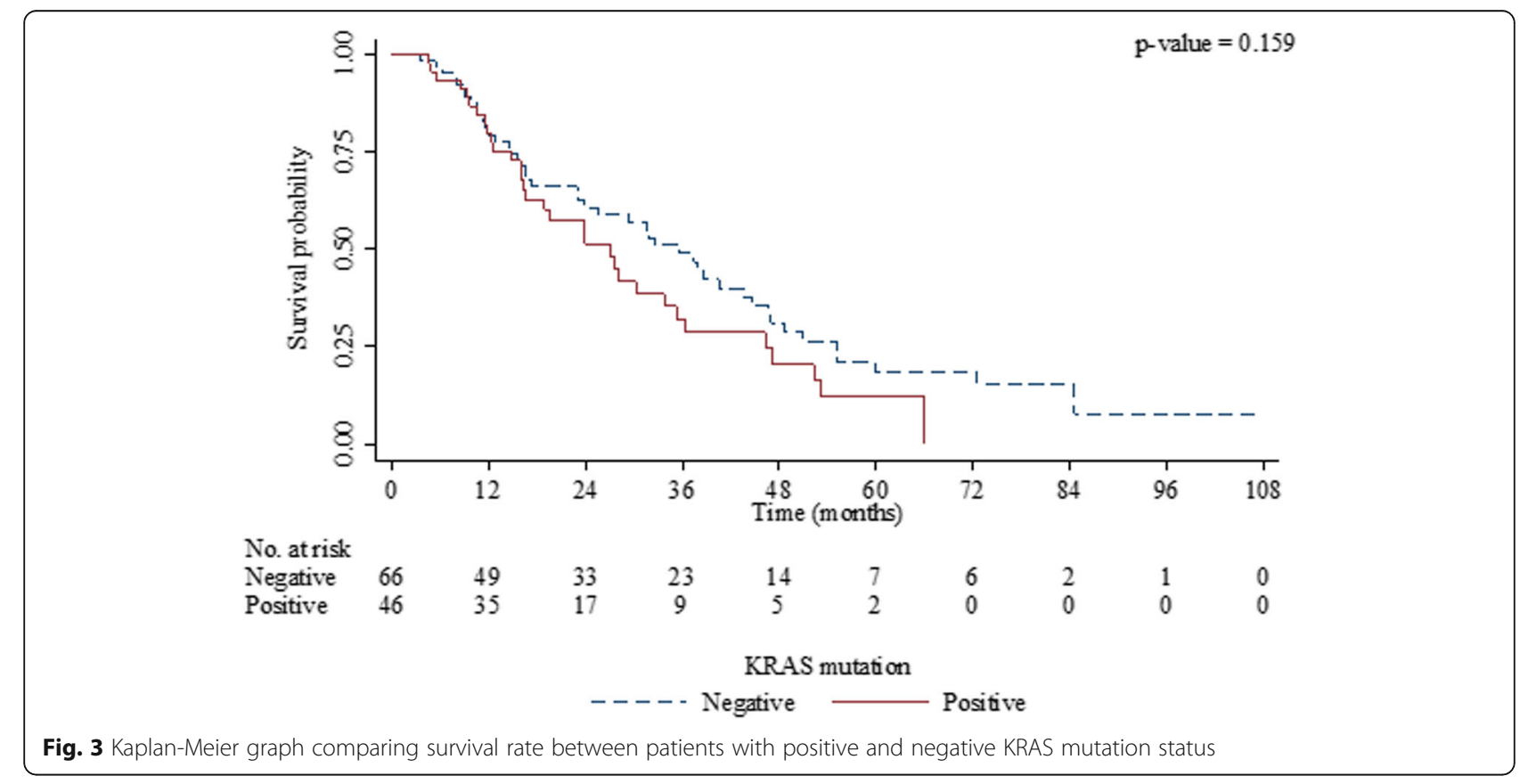




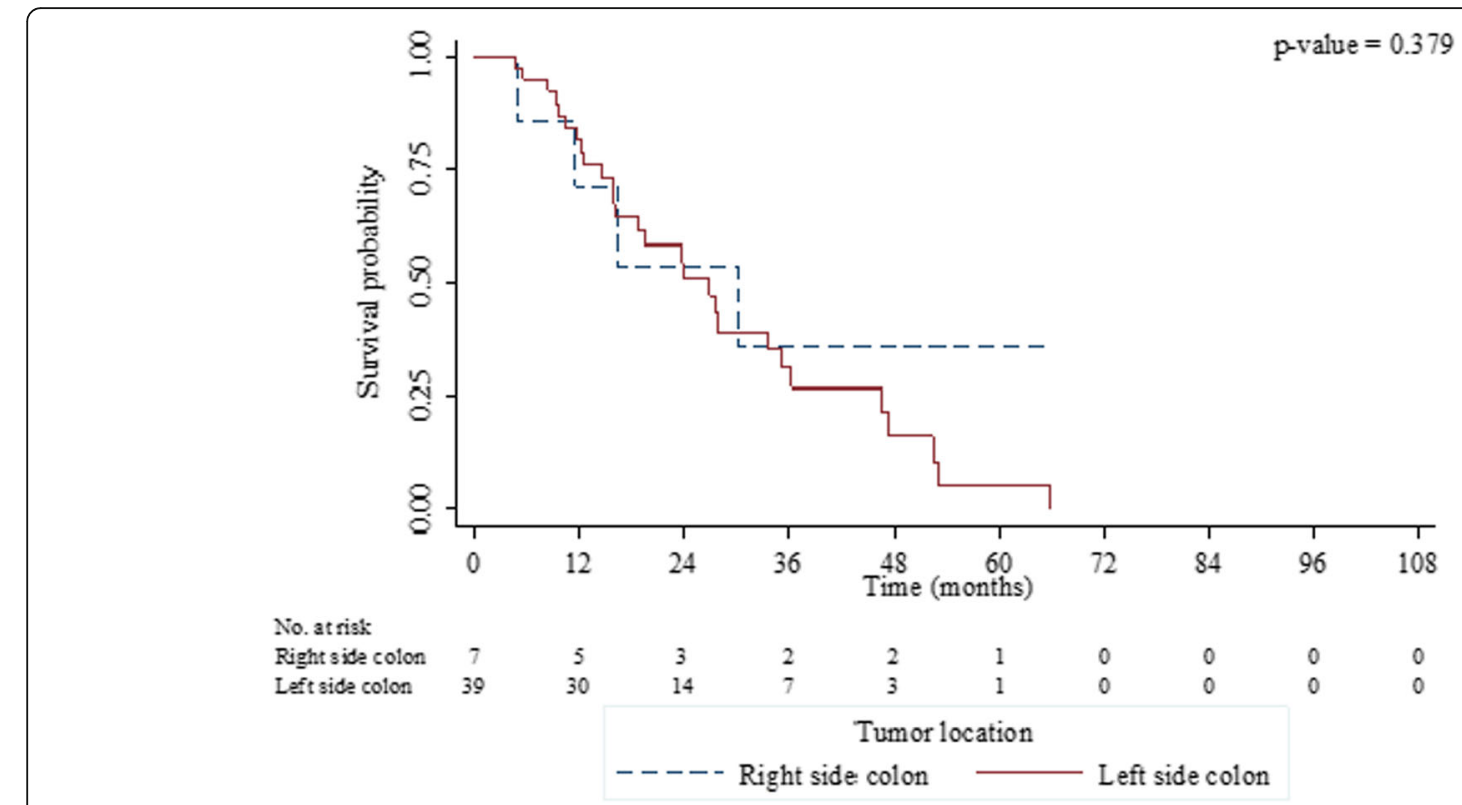

Fig. 4 Kaplan-Meier graph comparing survival rates between left- and right-side CRC in patients with positive KRAS mutation status

negative group, those with left-sided CRC had a higher survival rate $(P=0.005$; Fig. 5$)$.

\section{Comparison of tumor staging and survival analysis between groups}

There was no significant difference in $\mathrm{T}$ staging between the two KRAS groups

(P 0.177; Fig. 6)

\section{Discussion}

KRAS mutations are associated with multiple organ cancers including CRC [2, 15-17]. The presence of KRAS mutation in CRC is always associated with advanced tumor stage and presence of lymph node metastasis with poor response to treatment and outcome [2, 20, 23, 33, 41, 42]. For most CRC, CT is the routinely used imaging modality for tumor diagnosis, tumor staging, identifying patients who require neo-adjuvant therapy, and assessing treatment response

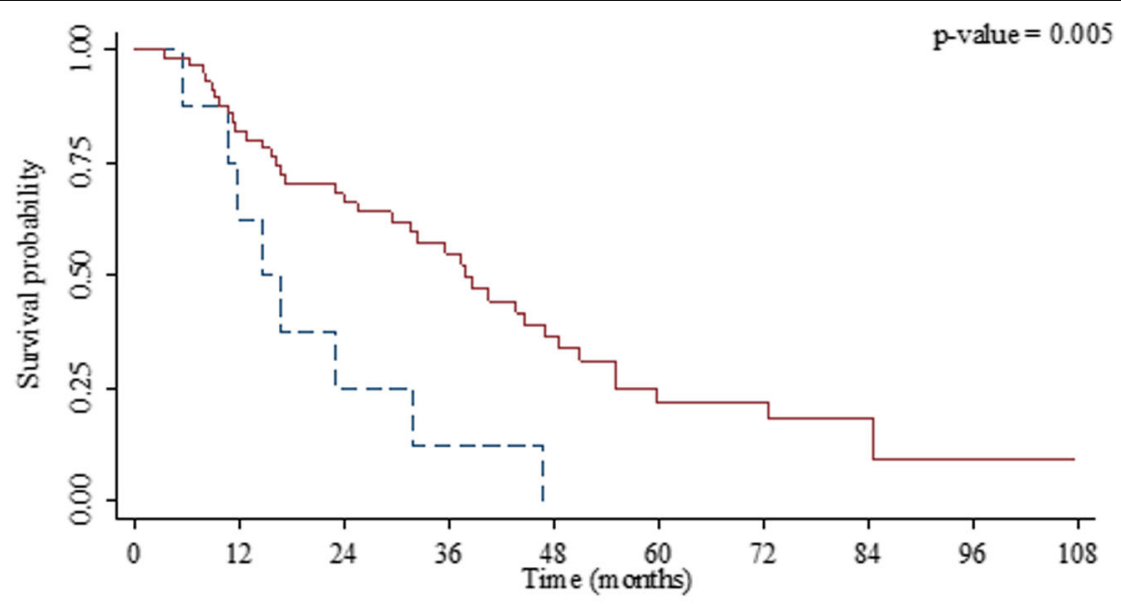

No. atrisk: $\begin{array}{lcccccccccc}\text { Right side colon } & 8 & 5 & 2 & 1 & 0 & 0 & 0 & 0 & 0 & 0 \\ \text { Left side colon } & 58 & 44 & 31 & 22 & 14 & 7 & 6 & 2 & 1 & 0\end{array}$

Tum or location - - - - Right side colon L Left side col on

Fig. 5 Kaplan-Meier graph comparing survival rates between left- and right-side CRC in patients with negative KRAS mutation status 


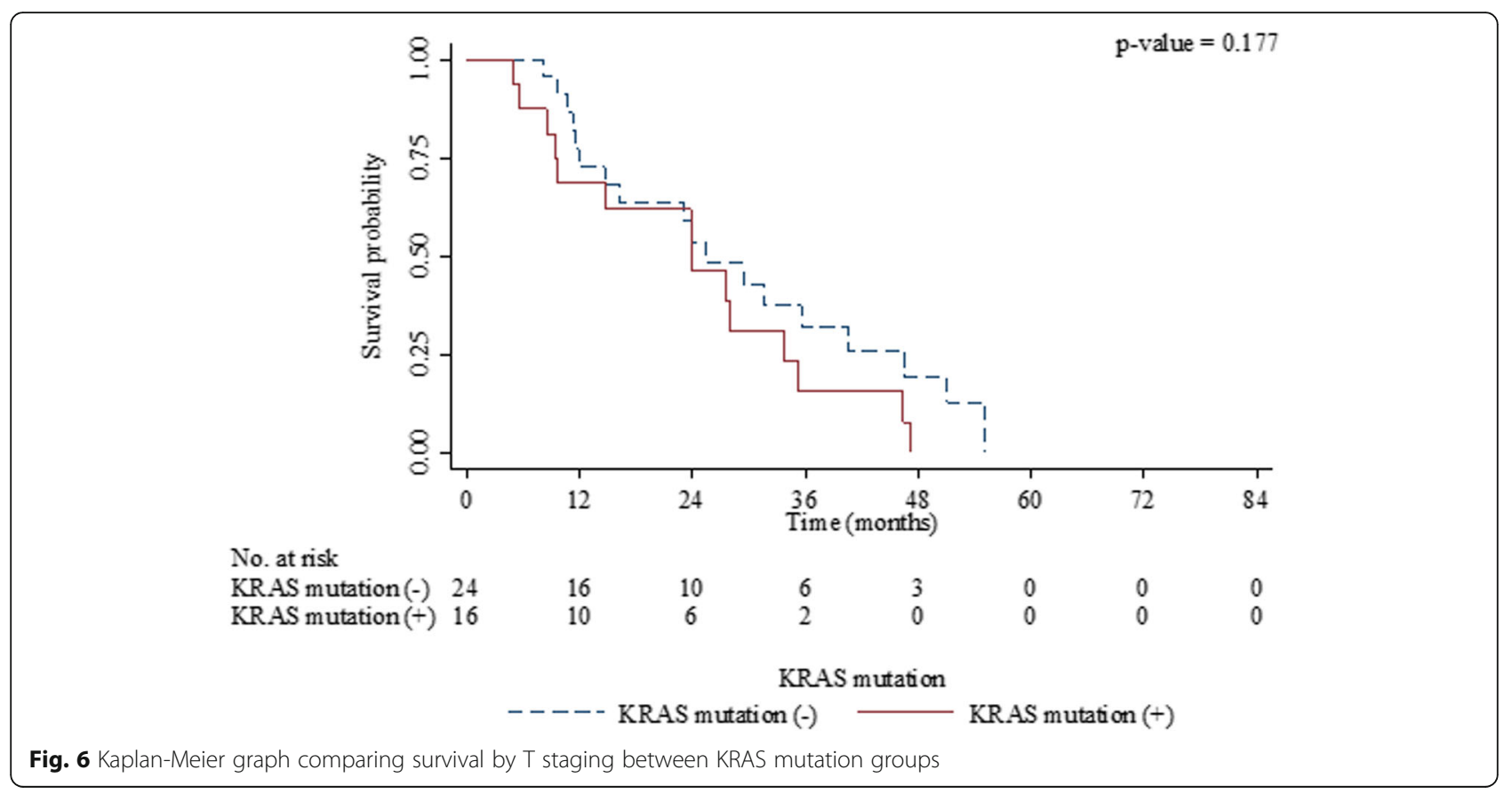

[43-46]. Recently, some reports have found that new generation CT scanners can offer high spatial resolution images with reliable rectal staging with low dose of radiation, particularly useful in patients who have contraindication to MRI [47, 48]. If used in conjunction with KRAS mutation status, CT may potentially be used as a noninvasive biomarker for deciding appropriate therapy selection and also predict patient prognosis.

Our study found that $90.24 \%$ of patients with KRAS mutations had necrosis of regional lymph node metastasis, whereas only $68.85 \%$ of KRAS wild type $(P=0.011)$ showed this finding. The results of our study were consistent with those of a study by Gonzalez et al. [49], who found cystic nodule metastasis containing tumor necrosis to be frequently associated with KRAS and BRAF mutation that have a micropapillary feature of CRC. The greater percentage of cases with nodal necrosis found in this study could be explained by using the KRAS mutation CRC base on the pathogenesis of classical adenoma-carcinoma associated pathway, which usually exhibits heterogeneous necrosis of the tumor [50, 51]. However, we found no significant difference between $\mathrm{N}$ and tumor staging in these KRAS mutations and wild-type groups, which differs from the results found in previous studies [20, 23, 33, 42].

KRAS mutation has been found to be associated with polypoid tumor growth patterns with higher staging and with fewer cases with flat tumor gross pattern in early staging [22, 32, 33, 52-57]. In this study, neither tumor size (including mean ATL, mean LTL, and mean ATL/ LTL) nor tumor morphology patterns differed significantly between CRC patients with and without KRAS mutation $(P=0.937, P=0.723$, and $P=0.888$, respectively). These differences may be related to the classical pathogenesis of CRC with adenoma-carcinoma sequence pathway proposed by Fearon and Vogelstein [58] and the other serrated pathway described by Jass and Smith [59] that serrate polyps, which may be associated with KRAS mutation, are generally smaller than 5 $\mathrm{mm}$ of the original size.

This study also found no significant difference in the occurrence of distant lymph node or distal organ metastases between the two groups. This contrasts with the findings of Cho et al. [36], who studied the correlation between KRAS mutation and 18F-FDG uptake in stage IV colorectal cancer patients and found that those with KRAS mutations had a higher incidence of lung metastases than those without.

Our survival outcome analysis showed that patients with KRAS mutation had a lower survival rate than those without. This result could be due to the higher rate of regional lymph node necrosis in this group, which can lead to poor disease outcomes. This finding could be involved in poorly differentiated carcinoma with microsatellite instability molecular pathway of adenoma-carcinoma sequence etiology [60, 61]. Necrosis within the tumor or lymph node indicates more aggressive tumor behavior, which leads to reduced survival. However, in patients without KRAS mutation, overall survival was higher in those with left-side CRC than those with right-side CRC $(P=0.005)$. This difference was not found in the KRAS mutation group. Some researchers have found that serrate adenocarcinoma pathway or carcinoma with microsatellite instability is usually related to right-side CRC and that these patients 
have less favorable 5-year survival outcomes [51, 62, 63]. However, our study found that tumors in both groups occurred primarily on the left side of the colon $(84.78 \%$ in those with KRAS mutation and $88.41 \%$ in those without; $P=0.584$ ).

\section{Limitations}

First limitation of this study is the small number of cases of KRAS mutation compared to those with KRAS wildtype CRC, which could have affected the results.

Second, this study included patients who had undergone a KRAS mutation test but not a BRAF gene mutation test, meaning that some of the patients in this study may have had a combination of KRAS and BRAF gene mutation (which occurs in $0.001 \%$ of the population). Further studies in larger populations who have undergone gene mutation tests could yield more accurate results.

Third, this was a retrospective study with variability in CT images from different CT scanners, especially those from outside institution with a limited spatial collimation and insufficient reconstruction. Further prospective study with the same high row number MDCT scanner with thin-collimation, high spatial resolution, and multiplanar reconstructions (MPRs) is needed to minimize image variability.

\section{Conclusion}

Imaging findings indicating necrosis of regional lymph node metastasis could be a biomarker that predicts KRAS mutation among patients with CRC and lower rates of survival.

\section{Abbreviations}

CRC: Colorectal cancer; KRAS: Mutations in Kirsten rat sarcoma; EGFR: Epidermal growth factor receptor; BRAF: b-Raf murine sarcoma viral oncogene homolog B1; NCCN: National Comprehensive Cancer Network; MRI: Magnetic resonance imaging; SUV $V_{\text {max: }}$ Maximum standardized uptake value; CT: Computed tomography; $\mathrm{HO}$ : Health object; PACS: Picture archiving and communication system; ATL: Axial tumor length; LTL: Longitudinal tumor length; TNM: Tumor (T), nodes (N), metastases (M); MPRs: Multiplanar reconstructions

\section{Acknowledgments}

We would like to acknowledge Dylan Southard (Research Affairs, Faculty of Medicine, Khon Kaen University, Thailand) for editing the manuscript.

\section{Authors' contributions}

All authors have read and approved the manuscript. J.P contributed to conceptualization, design of the study, image interpretation, writing, editing manuscript, submission and follow-up. P.C participated in design of study, imaging interpretation, data collection and manuscript writing. K.S participated in visualization and investigation. K.P participated in visualization and investigation. P.S participated in visualization and investigation. C.A participated in visualization and intestigation. R.M.L participated in visualization and intestigation. M.H contributed to supervision, reviewing and editing manuscript.

\section{Funding}

None

\section{Availability of data and materials}

The datasets used and/or analyzed during the current study are available from the corresponding author on reasonable request.

\section{Ethics approval and consent to participate}

Ethics approval was provided by the Ethics Committee of the Faculty of Medicine, Khon Kaen University, as instituted by the Helsinki Declaration, and this study was a retrospective study; for this type of study, formal consent is not required. The reference number of ethical approval is HE621442.

\section{Consent for publication}

All images in this manuscript contain no individual personal data.

\section{Competing interests}

The authors declare that they have no competing interests.

\section{Author details}

${ }^{1}$ Department of Radiology, Faculty of Medicine, Khon Kaen University, Khon Kaen District 40002, Thailand. '2Department of Surgery, Faculty of Medicine, Khon Kaen University, Khon Kaen District 40002, Thailand. ${ }^{3}$ Department of Pathology, Faculty of Medicine, Khon Kaen University, Khon Kaen District 40002, Thailand. ${ }^{4}$ Department of Radiology, Massachusetts General Hospital, Harvard Medical School, 55 Fruit Street, Boston, MA 02114, USA.

Received: 24 October 2020 Accepted: 14 December 2020

Published online: 06 January 2021

\section{References}

1. Siegel R, Naishadham D, Jemal A (2013) Global cancer statistics. CA Cancer J Clin 63:11-30

2. Italiano A, Hostein I, Soubeyran I et al (2010) KRAS and BRAF mutational status in primary colorectal tumors and related metastatic sites: biological and clinical implications. Ann Surg Oncol 17:1429-1434. https://doi.org/10. 1245/s10434-009-0864-Z

3. Karapetis CS, Khambata-Ford S, Jonker DJ et al (2008) K-ras mutations and benefit from cetuximab in advanced colorectal cancer. N Engl J Med 359: 1757-1765 https://doi.org/10.1056/NEJMoa0804385

4. Therkildsen C, Bergmann TK, Henrichsen-Schnack T et al (2014) The predictive value of KRAS, NRAS, BRAF, PIK3CA and PTEN for anti-EGFR treatment in metastatic colorectal cancer: a systematic review and metaanalysis. Acta Oncol 53:852-864 https://doi.org/10.3109/0284186X.2014. 895036

5. Benson $A B$, Venook $A P$, Cederquist $L$ et al (2017) Colon cancer, version 1. 2017, NCCN clinical practice guidelines in oncology. J Natl Compr Cancer Netw 15:370-398 https://doi.org/10.6004/jnccn.2017.0036

6. Amado RG, Wolf $M$, Peeters $M$ et al (2008) Wild-type KRAS is required for panitumumab efficacy in patients with metastatic colorectal cancer. J Clin Oncol 26:1626-1634 https://doi.org/10.1200/JCO.2007.14.7116

7. Van Cutsem E, Köhne C-H, Hitre E et al (2009) Cetuximab and chemotherapy as initial treatment for metastatic colorectal cancer. N Engl J Med 360:1408-1417 https://doi.org/10.1056/NEJMoa0805019

8. Lièvre $A$, Bachet J-B, Boige $V$ et al (2008) KRAS mutations as an independent prognostic factor in patients with advanced colorectal cancer treated with cetuximab. J Clin Oncol 26:374-379 https://doi.org/10.1200/JCO.2007.12. 5906

9. Baselga J, Rosen N (2008) Determinants of RASistance to anti-epidermal growth factor receptor agents. J Clin Oncol 26:1582-1584 https://doi.org/10. 1200/JCO.2007.15.3700

10. Bokemeyer C, Bondarenko I, Makhson A et al (2009) Fluorouracil, leucovorin, and oxaliplatin with and without cetuximab in the first-line treatment of metastatic colorectal cancer. J Clin Oncol 27:663-671 https://doi.org/10. 1200/JCO.2008.20.8397

11. De Roock W, Piessevaux H, De Schutter J et al (2008) KRAS wild-type state predicts survival and is associated to early radiological response in metastatic colorectal cancer treated with cetuximab. Ann Oncol 19:508-515 https://doi.org/10.1093/annonc/mdm496

12. Khambata-Ford S, Garrett CR, Meropol NJ et al (2007) Expression of epiregulin and amphiregulin and K-RAS mutation status predict disease control in metastatic colorectal cancer patients treated with cetuximab. J Clin Oncol 25:3230-3237 https://doi.org/10.1200/JCO.2006.10.5437 
13. Tejpar S, Celik I, Schlichting M et al (2012) Association of KRAS G13D tumor mutations with outcome in patients with metastatic colorectal cancer treated with first-line chemotherapy with or without cetuximab. J Clin Oncol 30:3570-3577 https://doi.org/10.1200/JCO.2012.42.2592

14. Levin-Sparenberg E, Bylsma LC, Lowe K et al (2020) A systematic literature review and meta-analysis describing the prevalence of KRAS, NRAS, and BRAF gene mutations in metastatic colorectal cancer. Gastroenterology Res 13:184-198 https://doi.org/10.14740/gr1167

15. Vittal A, Middinti A, Kasi Loknath Kumar A (2017) Are all mutations the same? A rare case report of coexisting mutually exclusive KRAS and BRAF mutations in a patient with metastatic colon adenocarcinoma. Case Rep Oncol Med 2017:2321052 https://doi.org/10.1155/2017/2321052

16. De Roock W, Claes B, Bernasconi D et al (2010) Effects of KRAS, BRAF, NRAS, and PIK3CA mutations on the efficacy of cetuximab plus chemotherapy in chemotherapy-refractory metastatic colorectal cancer: a retrospective consortium analysis. Lancet Oncol 11:753-762. https://doi.org/10.1016/ S1470-2045(10)70130-3

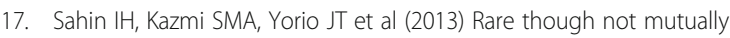
exclusive: a report of three cases of concomitant KRAS and BRAF mutation and a review of the literature. J Cancer 4:320-322 https://doi.org/10.7150/ jca.3619

18. Schwartzberg LS, Rivera F, Karthaus M et al (2014) PEAK: a randomized, multicenter phase II study of panitumumab plus modified fluorouracil, leucovorin, and oxaliplatin (mFOLFOX6) or bevacizumab plus mFOLFOX6 in patients with previously untreated, unresectable, wild-type KRAS exon 2 metastatic colorectal cancer. J Clin Oncol 32:2240-2247 https://doi.org/10 1200/JCO.2013.53.2473

19. Van Cutsem E, Lenz H-J, Köhne C-H et al (2015) Fluorouracil, leucovorin, and irinotecan plus cetuximab treatment and RAS mutations in colorectal cancer. J Clin Oncol 33:692-700 https://doi.org/10.1200/JCO. 2014.59.4812

20. Sameer AS, Chowdhri NA, Abdullah S et al (2009) Mutation pattern of K-ras gene in colorectal cancer patients of Kashmir: a report. Indian J Cancer 46: 219-225 https://doi.org/10.4103/0019-509X.52956

21. Bai B, Shan L, Xie B et al (2018) Mutations in KRAS codon 12 predict poor survival in Chinese patients with metastatic colorectal cancer. Oncol Lett 15: 3161-3166 https://doi.org/10.3892/ol.2017.7709

22. Yamagata S, Muto T, Uchida Y et al (1994) Lower incidence of K-ras codon 12 mutation in flat colorectal adenomas than in polypoid adenomas. Jpn J Cancer Res 85:147-151 https://doi.org/10.1111/j.13497006.1994.tb02075.x

23. Thebo JS, Senagore AJ, Reinhold DS, Stapleton SR (2000) Molecular staging of colorectal cancer: K-ras mutation analysis of lymph nodes upstages Dukes B patients. Dis Colon Rectum 43:155-159; discussion 159-162. https:// doi.org/10.1007/bf02236973

24. Yokota T (2012) Are KRAS/BRAF mutations potent prognostic and/or predictive biomarkers in colorectal cancers? Anti Cancer Agents Med Chem 12:163-171 https://doi.org/10.2174/187152012799014968

25. Ren J, Li G, Ge J et al (2012) Is K-ras gene mutation a prognostic factor for colorectal cancer: a systematic review and meta-analysis. Dis Colon Rectum 55:913-923 https://doi.org/10.1097/DCR.0b013e318251d8d9

26. Díaz-Rubio E, Gómez-España A, Massutí B et al (2012) Role of Kras status in patients with metastatic colorectal cancer receiving first-line chemotherapy plus bevacizumab: a TTD group cooperative study. PLoS One 7:e47345 https://doi.org/10.1371/journal.pone.0047345

27. Malapelle U, Bellevicine C, Salatiello M et al (2012) Sanger sequencing in routine KRAS testing: a review of 1720 cases from a pathologist's perspective. J Clin Pathol 65:940-944 https://doi.org/10.1136/jclinpath-2012-200773

28. Douillard J-Y, Siena S, Cassidy J et al (2010) Randomized, phase III trial of panitumumab with infusional fluorouracil, leucovorin, and oxaliplatin (FOLFOX4) versus FOLFOX4 alone as first-line treatment in patients with previously untreated metastatic colorectal cancer: the PRIME study. J Clin Oncol 28:4697-4705 https://doi.org/10.1200/JCO.2009.27.4860

29. Tsilimigras DI, Ntanasis-Stathopoulos I, Bagante F et al (2018) Clinical significance and prognostic relevance of KRAS, BRAF, PI3K and TP53 genetic mutation analysis for resectable and unresectable colorectal liver metastases: a systematic review of the current evidence. Surg Oncol 27: 280-288 https://doi.org/10.1016/j.suronc.2018.05.012

30. Laghi A, Ferri M, Catalano C et al (2002) Local staging of rectal cancer with MRI using a phased array body coil. Abdom Imaging 27:425-431 https://doi. org/10.1007/s00261-001-0123-7
31. Jo SJ, Kim SH (2019) Association between oncogenic RAS mutation and radiologic-pathologic findings in patients with primary rectal cancer. Quant Imaging Med Surg 9:238-246 https://doi.org/10.21037/ gims.2018.12.10

32. Xu Y, Xu Q, Ma Y et al (2019) Characterizing MRI features of rectal cancers with different KRAS status. BMC Cancer 19:1111 https://doi.org/10.1186/ s12885-019-6341-6

33. Shin YR, Kim KA, Im S et al (2016) Prediction of KRAS mutation in rectal cancer using MRI. Anticancer Res 36:4799-4804 https://doi.org/10.21873/ anticanres.11039

34. Cui Y, Cui X, Yang X et al (2019) Diffusion kurtosis imaging-derived histogram metrics for prediction of KRAS mutation in rectal adenocarcinoma: preliminary findings. J Magn Reson Imaging 50:930-939 https://doi.org/10.1002/jmri.26653

35. Arslan E, Aksoy T, Gürsu RU et al (2020) The prognostic value of ${ }^{18} \mathrm{~F}-\mathrm{FDG}$ PET/CT and KRAS mutation in colorectal cancers. Mol Imaging Radionucl Ther 29:17-24 https://doi.org/10.4274/mirt.galenos.2019.33866

36. Cho A, Jo K, Hwang SH et al (2017) Correlation between KRAS mutation and 18F-FDG uptake in stage IV colorectal cancer. Abdom Radiol (NY) 42: 1621-1626 https://doi.org/10.1007/s00261-017-1054-2

37. Chen S-W, Lin C-Y, Ho C-M et al (2015) Genetic alterations in colorectal cancer have different patterns on 18F-FDG PET/CT. Clin Nucl Med 40:621626 https://doi.org/10.1097/RLU.0000000000000830

38. Chen S-W, Chiang H-C, Chen WT-L et al (2014) Correlation between PET/CT parameters and KRAS expression in colorectal cancer. Clin Nucl Med 39: 685-689 https://doi.org/10.1097/RLU.0000000000000481

39. Chen S-W, Shen W-C, Chen WT-L et al (2019) Metabolic imaging phenotype using radiomics of [18 F]FDG PET/CT associated with genetic alterations of colorectal cancer. Mol Imaging Biol 21:183-190 https://doi.org/10.1007/ s11307-018-1225-8

40. Puccini A, Marshall JL, Salem ME (2018) Molecular variances between rightand left-sided colon cancers. Curr Colorectal Cancer Rep 14:152-158

41. Oliveira C, Velho S, Moutinho C et al (2007) KRAS and BRAF oncogenic mutations in MSS colorectal carcinoma progression. Oncogene 26:158-163 https://doi.org/10.1038/sj.onc.1209758

42. Al-Mulla F, Going JJ, Sowden ET et al (1998) Heterogeneity of mutant versus wild-type Ki-ras in primary and metastatic colorectal carcinomas, and association of codon-12 valine with early mortality. J Pathol 185: 130-138 https://doi.org/10.1002/(SICI)1096-9896(199806)185:2<130::AIDPATH85>3.0.CO:2-M

43. Horvat N, Raj A, Liu S et al (2019) Ct colonography in preoperative staging of colon cancer: evaluation of FOxTROT inclusion criteria for neoadjuvant therapy. AJR Am J Roentgenol 212:94-102 https://doi.org/10.2214/AJR.18.19928

44. Wiegering $A$, Kunz M, Hussein M et al (2015) Diagnostic value of preoperative CT scan to stratify colon cancer for neoadjuvant therapy. Int J Color Dis 30:1067-1073 https://doi.org/10.1007/s00384-015-2265-z

45. Nørgaard A, Dam C, Jakobsen A et al (2014) Selection of colon cancer patients for neoadjuvant chemotherapy by preoperative CT scan. Scand J Gastroenterol 49:202-208 https://doi.org/10.3109/00365521.2013.862294

46. Gursoy Coruh A, Peker E, Elhan A et al (2019) Evaluation of extramural venous invasion by diffusion-weighted magnetic resonance imaging and computed tomography in rectal adenocarcinoma. Can Assoc Radiol J 70: 457-465 https://doi.org/10.1016/j.carj.2019.06.006

47. Ippolito D, Drago SG, Talei Franzesi CR et al (2017) Diagnostic value of fourth-generation iterative reconstruction algorithm with low-dose CT protocol in assessment of mesorectal fascia invasion in rectal cancer: comparison with magnetic resonance. Abdom Radiol (NY) 42:2251-2260 https://doi.org/10.1007/s00261-017-1138-z

48. Ippolito D, Drago SG, Franzesi CT et al (2016) Rectal cancer staging: multidetector-row computed tomography diagnostic accuracy in assessment of mesorectal fascia invasion. World J Gastroenterol 22:48914900 https://doi.org/10.3748/wjg.v22.i20.4891

49. Gonzalez RS, Huh WJ, Cates JMM et al (2017) Micropapillary colorectal carcinoma: clinical, pathological and molecular properties, including evidence of epithelial-mesenchymal transition. Histopathology 70:223-231 https://doi.org/10.1111/his.13068

50. Pino MS, Chung DC (2010) The chromosomal instability pathway in colon cancer. Gastroenterology 138:2059-2072 https://doi.org/10.1053/j.gastro. 2009.12.065

51. Mäkinen MJ (2007) Colorectal serrated adenocarcinoma. Histopathology 50: 131-150 https://doi.org/10.1111/j.1365-2559.2006.02548.x 
52. Fujimori T, Satonaka K, Yamamura-Idei Y et al (1994) Non-involvement of ras mutations in flat colorectal adenomas and carcinomas. Int J Cancer 57:5155 https://doi.org/10.1002/ijc.2910570110

53. Hasegawa H, Ueda M, Watanabe M et al (1995) K-ras gene mutations in early colorectal cancer... flat elevated vs polyp-forming cancer. Oncogene 10:1413-1416

54. Voorham QJM, Rondagh EJA, Knol DL et al (2013) Tracking the molecular features of nonpolypoid colorectal neoplasms: a systematic review and meta-analysis. Am J Gastroenterol 108:1042-1056 https://doi.org/10.1038/ ajg.2013.126

55. Yamagata S, Muto T, Uchida Y et al (1995) Polypoid growth and K-ras codon 12 mutation in colorectal cancer. Cancer 75:953-957 https://doi.org/ 10.1002/1097-0142(19950215)75:4<953::aid-cncr2820750409>3.0.co;2-r

56. Kaji E, Kato J, Suzuki $H$ et al (2011) Analysis of K-ras, BRAF, and PIK3CA mutations in laterally-spreading tumors of the colorectum. J Gastroenterol Hepatol 26:599-607 https://doi.org/10.1111/j.1440-1746.2010.06485.x

57. Vogelstein B, Fearon ER, Hamilton SR et al (1988) Genetic alterations during colorectal-tumor development. N Engl J Med 319:525-532 https:/doi.org/ 10.1056/NEJM198809013190901

58. Fearon ER, Vogelstein B (1990) A genetic model for colorectal tumorigenesis. Cell 61:759-767. https://doi.org/10.1016/0092-8674(90)90186-i

59. Jass JR, Smith M (1992) Sialic acid and epithelial differentiation in colorectal polyps and cancer--a morphological, mucin and lectin histochemical study. Pathology 24:233-242 https://doi.org/10.3109/00313029209068874

60. Snover DC (2011) Sessile serrated adenoma/polyp of the large intestine: a potentially aggressive lesion in need of a new screening strategy. Dis Colon Rectum 54:1205-1206 https://doi.org/10.1097/DCR.0b013e318228f8bc

61. Koinuma K, Shitoh K, Miyakura Y et al (2004) Mutations of BRAF are associated with extensive hMLH1 promoter methylation in sporadic colorectal carcinomas. Int J Cancer 108:237-242 https://doi.org/10.1002/ijc. 11523

62. Bosman FT, Carneiro F, Hruban RH, Theise ND (2010) WHO classification of tumours of the digestive system. IARC Press, Lyon

63. García-Solano J, Pérez-Guillermo M, Conesa-Zamora P et al (2010) Clinicopathologic study of 85 colorectal serrated adenocarcinomas: furthe insights into the full recognition of a new subset of colorectal carcinoma. Hum Pathol 41:1359-1368 https://doi.org/10.1016/j.humpath.2010.04.002

\section{Publisher's Note}

Springer Nature remains neutral with regard to jurisdictional claims in published maps and institutional affiliations.

\section{Submit your manuscript to a SpringerOpen ${ }^{\circ}$ journal and benefit from:}

- Convenient online submission

- Rigorous peer review

- Open access: articles freely available online

- High visibility within the field

- Retaining the copyright to your article

Submit your next manuscript at $\boldsymbol{\nabla}$ springeropen.com 